\title{
(6) \\ Computational fluid dynamics modelling in cardiovascular medicine
} OPEN ACCESS

\author{
Paul D Morris, ${ }^{1,2,3}$ Andrew Narracott, ${ }^{1,2}$ Hendrik von Tengg-Kobligk, ${ }^{4}$ \\ Daniel Alejandro Silva Soto, ${ }^{1,2}$ Sarah Hsiao, ${ }^{1}$ Angela Lungu, ${ }^{1,2}$ Paul Evans, ${ }^{1,2}$ \\ Neil W Bressloff, ${ }^{5}$ Patricia V Lawford, ${ }^{1,2}$ D Rodney Hose, ${ }^{1,2}$ Julian P Gunn ${ }^{1,2,3}$
}

\begin{abstract}
- Additional material is published online. To view please visit the journal (http:// dx.doi.org/10.1136/heartjnl2015-308044)

${ }^{1}$ Department of Cardiovascular Science, University of Sheffield, Sheffield, UK

${ }^{2}$ Insigneo Institute for In Silico Medicine, Sheffield, UK

${ }^{3}$ Department of Cardiology, Sheffield Teaching Hospitals

NHS Trust, Sheffield, UK

${ }^{4}$ University Institute for

Diagnostic, Interventional and Pediatric Radiology, University Hospital of Bern, Inselspital, Bern, Switzerland

${ }^{5}$ Faculty of Engineering \& the Environment, University of Southampton, Southampton, UK
\end{abstract}

\section{Correspondence to} Dr Paul D Morris, Medical Physics Group, Department of Cardiovascular Science, University of Sheffield, The Medical School, Beech Hill Road, Sheffield S102RX, UK. paulmorris@doctors.org.uk

Received 23 April 2015 Revised 20 September 2015 Accepted 21 September 2015 Published Online First 28 October 2015

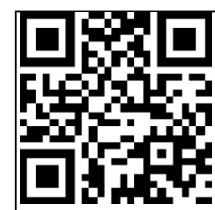

Open Access Scan to access mor free content

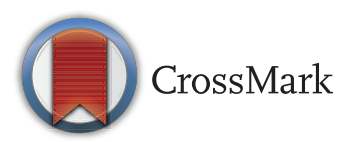

To cite: Morris $P D$, Narracott A, von TenggKobligk $\mathrm{H}$, et al. Heart 2016;102:18-28.

\section{ABSTRACT}

This paper reviews the methods, benefits and challenges associated with the adoption and translation of computational fluid dynamics (CFD) modelling within cardiovascular medicine. CFD, a specialist area of mathematics and a branch of fluid mechanics, is used routinely in a diverse range of safety-critical engineering systems, which increasingly is being applied to the cardiovascular system. By facilitating rapid, economical, low-risk prototyping, CFD modelling has already revolutionised research and development of devices such as stents, valve prostheses, and ventricular assist devices. Combined with cardiovascular imaging, CFD simulation enables detailed characterisation of complex physiological pressure and flow fields and the computation of metrics which cannot be directly measured, for example, wall shear stress. CFD models are now being translated into clinical tools for physicians to use across the spectrum of coronary, valvular, congenital, myocardial and peripheral vascular diseases. CFD modelling is apposite for minimally-invasive patient assessment. Patient-specific (incorporating data unique to the individual) and multi-scale (combining models of different length- and time-scales) modelling enables individualised risk prediction and virtual treatment planning. This represents a significant departure from traditional dependence upon registry-based, populationaveraged data. Model integration is progressively moving towards 'digital patient' or 'virtual physiological human' representations. When combined with population-scale numerical models, these models have the potential to reduce the cost, time and risk associated with clinical trials. The adoption of CFD modelling signals a new era in cardiovascular medicine. While potentially highly beneficial, a number of academic and commercial groups are addressing the associated methodological, regulatory, education- and service-related challenges.

\section{INTRODUCTION}

Computational fluid dynamics (CFD) is a wellestablished tool used in engineering, in many areas of which it has become the primary method for design and analysis. Bioengineers have adopted CFD to study complex physiological flows and have demonstrated their potential. ${ }^{1}$ There is increasing interest in applying these methods in cardiovascular medicine. ${ }^{2}$ CFD-based techniques are being used to build complex computer representations (in silico models) of the cardiovascular system in health and disease. CFD modelling is a new field within cardiovascular medicine, enhancing diagnostic assessment, device design and clinical trials.
It can predict physiological responses to intervention and compute previously unmeasurable haemodynamic parameters. ${ }^{4}$ As CFD modelling continues to translate into clinical tools, it is important that clinicians understand the principles, benefits and limitations of these techniques. This article explores these topics using state-of-the-art examples in key clinical areas, highlighting applications likely to impact clinical practice within the next 5 years (table 1).

\section{WHAT IS CFD?}

CFD is a specialist area of mathematics and a branch of fluid mechanics. It is used in the design of many safety-critical systems, including aircraft and vehicles, by solving differential equations to simulate fluid flow. A glossary of uesful terms is provided in table 2.

For incompressible flows, almost all CFD analyses solve the Navier-Stokes and continuity equations which govern fluid motion. These equations are non-linear, partial differential equations based upon the principle of conservation of mass and momentum. Simplification of these equations yields familiar formulae (eg, those of Bernoulli and Poiseuille); but for complex geometries analytical solutions are not possible, so specialised software applications (CFD solvers) calculate approximate numerical solutions. Non-linearity, due to convective fluid acceleration, makes this challenging, especially in three dimensional (3D) models; so CFD analyses require significant computational power and time.

\section{CFD MODEL COMPLEXITY}

The applications reviewed in this paper focus on 3D CFD analyses of local regions of the vasculature because this is where promising applications are beginning to translate and impact upon clinical medicine. There is a long history of simplification of the governing equations to lower spatial dimensions. Table 3 summarises the relationship between these approaches and provides clinical examples of their use.

2D analyses typically assume symmetry of the solution about the central axis, 1D models capture variation of the solution along the axial direction only, and OD representations lump the behaviour of vascular regions into a model with no spatial dimensions, hence the term 'lumped-parameter models'. Due to the breadth of the literature covering application of these techniques to cardiovascular haemodynamics, the interested reader is referred to recent reviews of the state-of-the-art. ${ }^{45} 46$ 
Table 1 Summary of CFD modelling applications in cardiovascular medicine

\begin{tabular}{|c|c|c|c|c|c|}
\hline Area & Clinical applications & Data and evidence & Potential clinical impact & Limitations and challenges & References \\
\hline $\begin{array}{l}\text { Coronary artery } \\
\text { disease and } \\
\text { physiology }\end{array}$ & $\begin{array}{l}\text { Models based upon } \\
\text { coronary angiography (CT } \\
\text { linvasive) to compute } \\
\text { physiological coronary lesion } \\
\text { significance less invasively }\end{array}$ & $\begin{array}{l}\text { Multiple trials } \\
\text { demonstrating broadly good } \\
\text { agreement between } \\
\text { standard and CFD-derived } \\
\text { FFR (vFFR). Lesion } \\
\text { significance established in } \\
\sim 80-90 \%\end{array}$ & $\begin{array}{l}\text { Widened access to the } \\
\text { benefits of physiological } \\
\text { lesion assessment; vFFR lacks } \\
\text { the practical limitations that } \\
\text { restrict use of the invasive } \\
\text { technique. Virtual stenting } \\
\text { enables planning and } \\
\text { selection of optimal } \\
\text { treatment strategy }\end{array}$ & $\begin{array}{l}\text { Accurate vessel reconstruction } \\
\text { and patient-specific tuning of } \\
\text { the model boundary } \\
\text { conditions (especially those of } \\
\text { myocardial resistance) }\end{array}$ & 5678 \\
\hline Valve prostheses & $\begin{array}{l}\text { Evaluation and optimisation } \\
\text { of prosthetic valve design } \\
\text { from a haemodynamic } \\
\text { perspective }\end{array}$ & $\begin{array}{l}\text { Included in the design } \\
\text { dossier given to RA for } \\
\text { approval before use in } \\
\text { humans. Third party, } \\
\text { comparative studies are in } \\
\text { engineering literature }\end{array}$ & $\begin{array}{l}\text { CFD modelling enables the } \\
\text { best design, yielding the } \\
\text { optimal haemodynamics and } \\
\text { lowest achievable risk of } \\
\text { design-related thrombosis } \\
\text { and thromboembolism }\end{array}$ & $\begin{array}{l}\text { Dependence upon validity of } \\
\text { models to interpret fluid } \\
\text { stresses in terms of } \\
\text { thrombogenic/haemolytic } \\
\text { potential. Primarily relates to } \\
\text { mechanical valves. Tissue } \\
\text { valve leaflets remain } \\
\text { challenging to model }\end{array}$ & 91011 \\
\hline $\begin{array}{l}\text { Native valve } \\
\text { haemodynamics in } \\
\text { health and disease }\end{array}$ & $\begin{array}{l}\text { Non-invasive computation } \\
\text { and quantification of } \\
\text { trans-valvular pressure drop } \\
\text { and regurgitant fraction } \\
\text { from CT imaging }\end{array}$ & $\begin{array}{l}\text { Accurate 3D simulations in } \\
\text { patient-specific models with } \\
\text { valves in open and closed } \\
\text { states to predict } \\
\text { transvalvular dynamics in } \\
\text { diseased states }\end{array}$ & $\begin{array}{l}\text { Improved objective } \\
\text { assessment and surveillance } \\
\text { of valve disease from } \\
\text { non-invasive imaging data }\end{array}$ & $\begin{array}{l}\text { Requires high quality 3D } \\
\text { images of valve orifice-not } \\
\text { routinely generated. } \\
\text { Balancing the requirement for } \\
\text { complex dynamic simulation } \\
\text { (FSI) vs simpler models (valve } \\
\text { open/closed) }\end{array}$ & 1213 \\
\hline Aortic aneurysm & $\begin{array}{l}\text { Provides quantitative } \\
\text { haemodynamic data for } \\
\text { non-invasive imaging to } \\
\text { emphasise the significance } \\
\text { of findings. Virtual therapy } \\
\text { simulation/predictions }\end{array}$ & $\begin{array}{l}\text { No published outcome } \\
\text { trials, only single centre } \\
\text { experiences and small } \\
\text { cohorts using different } \\
\text { boundary condition and } \\
\text { computational methods }\end{array}$ & $\begin{array}{l}\text { To better predict aneurysm } \\
\text { progression and risk of } \\
\text { rupture. Prediction of } \\
\text { putative therapeutic effects. } \\
\text { Individualised care and } \\
\text { reduction in costs for } \\
\text { unnecessary follow-up } \\
\text { imaging and visits }\end{array}$ & $\begin{array}{l}\text { Impact of low image contrast } \\
\text { structures of aortic aneurysm } \\
\text { (eg, wall, thrombus) as well } \\
\text { as wall motion needs to be } \\
\text { further assessed. CFD alone is } \\
\text { probably limited and needs to } \\
\text { be complemented by, for } \\
\text { example, FSI }\end{array}$ & 3141516 \\
\hline Aortic dissection & $\begin{array}{l}\text { Pathophysiological } \\
\text { conditions in true and false } \\
\text { lumen computed from } \\
\text { non-invasive boundary } \\
\text { conditions (CT and MRI } \\
+\mathrm{PC}) \text {. Effects of virtual } \\
\text { therapy. }\end{array}$ & $\begin{array}{l}\text { No published outcome } \\
\text { trials, only single centre } \\
\text { experiences and small } \\
\text { cohorts using different } \\
\text { boundary conditions and } \\
\text { computational methods }\end{array}$ & $\begin{array}{l}\text { Computed pressure and flow } \\
\text { conditions used to guide } \\
\text { (semi-) invasive therapeutic } \\
\text { procedure decisions. } \\
\text { Physiological effects of } \\
\text { therapies can be simulated } \\
\text { and better predicted }\end{array}$ & $\begin{array}{l}\text { Significant early and late } \\
\text { re-modelling of the dissected } \\
\text { wall. Entry, re-entry and } \\
\text { communication channels } \\
\text { create a complex } \\
\text { computational scenario. } \\
\text { CFD alone might be limited. } \\
\text { A potential role for FSI }\end{array}$ & 171819 \\
\hline Stent design & $\begin{array}{l}\text { Prediction of WSS and } \\
\text { related metrics that } \\
\text { influence endothelial } \\
\text { function and NH due to } \\
\text { stent-induced } \\
\text { haemodynamic disturbance }\end{array}$ & $\begin{array}{l}\text { Turbulent or disturbed } \\
\text { laminar flow reduces WSS } \\
\text { stimulating adverse vessel } \\
\text { remodelling. NH } \\
\text { preferentially accumulates in } \\
\text { these regions }\end{array}$ & $\begin{array}{l}\text { Not possible to measure } \\
\text { arterial WSS in vivo, } \\
\text { especially in the vicinity of } \\
\text { stent struts post-PCI. } \\
\text { Modelling provides detailed } \\
\text { analysis of flow, and the } \\
\text { influence of stent design } \\
\text { through patient-specific } \\
\text { reconstructions, enabling the } \\
\text { optimal stent design to be } \\
\text { achieved }\end{array}$ & $\begin{array}{l}\text { High resolution imaging, } \\
\text { vessel reconstruction and } \\
\text { boundary conditions are } \\
\text { challenging. CFD simulations } \\
\text { demand fine computational } \\
\text { meshes and time-resolved } \\
\text { pulsatility. Run-times are } \\
\text { long, even with high } \\
\text { performance computing }\end{array}$ & 2021222324252627 \\
\hline Cerebral aneurysm & $\begin{array}{l}\text { Prediction of } \\
\text { intra-aneurysmal flow, } \\
\text { stasis, jet impingement and } \\
\text { WSS from MRI and CT } \\
\text { cerebral angiography data }\end{array}$ & $\begin{array}{l}\text { Published data on } \\
\text { association between WSS, } \\
\text { aneurysm initiation, growth, } \\
\text { and potentially rupture }\end{array}$ & $\begin{array}{l}\text { Detailed, individualised } \\
\text { haemodynamic analysis with } \\
\text { potential for risk prediction. } \\
\text { Impact of putative treatments } \\
\text { on local haemodynamics } \\
\text { evaluated in silico }\end{array}$ & $\begin{array}{l}\text { Difficulty interpreting complex } \\
\text { and detailed WSS results. } \\
\text { Understanding how results } \\
\text { translate to rupture risk. } \\
\text { Validation of rupture } \\
\text { predictions-a rare event }\end{array}$ & 42829 \\
\hline $\begin{array}{l}\text { Pulmonary } \\
\text { hypertension (PH) }\end{array}$ & $\begin{array}{l}\text { Greater insights into } \\
\text { complex PH physiology. } \\
\text { Increasing interest in } \\
\text { non-invasive diagnosis and } \\
\text { monitoring of response to } \\
\text { treatment }\end{array}$ & $\begin{array}{l}\text { Models based on MR flows } \\
\text { demonstrated to } \\
\text { differentiate between } \\
\text { healthy volunteers and to } \\
\text { stratify PH subcategories }\end{array}$ & $\begin{array}{l}\text { Imaging-based modelling of } \\
\text { pulmonary haemodynamics } \\
\text { can reduce the requirement } \\
\text { for right heart } \\
\text { catheterisation. Models show } \\
\text { association between reduced } \\
\text { WSS and invasive PH metrics. } \\
\text { PH subtype characteristics } \\
\text { simulated to understand the } \\
\text { structural changes } \\
\text { contributing to increased PAP }\end{array}$ & $\begin{array}{l}\text { Spatial resolution of imaging } \\
\text { and segmentation protocols. } \\
\text { The use of a pressure } \\
\text { surrogate measure. The } \\
\text { presence of many outlets } \\
\text { requiring many measurements } \\
\text { to tune the outflow boundary } \\
\text { conditions }\end{array}$ & 30313233 \\
\hline $\begin{array}{l}\text { Arterial wall shear } \\
\text { stress (WSS) }\end{array}$ & $\begin{array}{l}\text { WSS mapping, } \\
\text { cross-referenced with }\end{array}$ & $\begin{array}{l}\text { An abnormal WSS pattern } \\
\text { has been correlated with }\end{array}$ & $\begin{array}{l}\text { Ultimate understanding of } \\
\text { the development and }\end{array}$ & $\begin{array}{l}\text { A detailed vascular geometry } \\
\text { is essential for an accurate }\end{array}$ & 20212225 \\
\hline
\end{tabular}


Table 1 Continued

\begin{tabular}{|c|c|c|c|c|c|}
\hline Area & Clinical applications & Data and evidence & Potential clinical impact & Limitations and challenges & References \\
\hline & $\begin{array}{l}\text { vascular disease phenotype, } \\
\text { is contributing to the } \\
\text { understanding of cellular } \\
\text { biology }\end{array}$ & $\begin{array}{l}\text { vascular diseases, including } \\
\text { atherosclerosis, aneurysm } \\
\text { and post-stent NH }\end{array}$ & $\begin{array}{l}\text { progression of } \\
\text { atherosclerosis. WSS map } \\
\text { combined with multi-scale } \\
\text { modelling may inform clinical } \\
\text { practice, such as the site of } \\
\text { rupture in aneurysm, and } \\
\text { severity of in-stent restenosis. }\end{array}$ & $\begin{array}{l}\text { WSS map. Acquisition of } \\
\text { patient specific boundary } \\
\text { conditions remains clinically } \\
\text { challenging. }\end{array}$ & \\
\hline Heart failure & $\begin{array}{l}\text { Models based upon CT and } \\
\text { MR help compute } \\
\text { haemodynamics and the } \\
\text { spatio-temporal distributions } \\
\text { of pressure and myocardial } \\
\text { stress/strain }\end{array}$ & $\begin{array}{l}\text { CFD/FSI models replicate } \\
\text { realistic pathophysiology in } \\
\text { models of health and } \\
\text { disease (eg, HFREF, HFPEF, } \\
\text { HCM, DCM, and RWMA } \\
\text { post-MI) }\end{array}$ & $\begin{array}{l}\text { Additional haemodynamic } \\
\text { data potentially enables early } \\
\text { diagnosis and stratifies } \\
\text { disease phenotypes and } \\
\text { severities. Characterising } \\
\text { complex vortex flows } \\
\text { identifies areas of flow } \\
\text { stagnation and thrombus risk }\end{array}$ & $\begin{array}{l}\text { Resolution of imaging and } \\
\text { reconstruction (representing } \\
\text { trabeculae and papillary } \\
\text { muscles). Tuning with realistic } \\
\text { boundary conditions. } \\
\text { Requirement for FSI in many } \\
\text { models }\end{array}$ & 23435363738394041 \\
\hline CRT & $\begin{array}{l}\text { Coupled electro-mechanical } \\
\text { models of the ventricle } \\
\text { incorporating CFD } \\
\text { (multi-physics models) used } \\
\text { to investigate heart function }\end{array}$ & $\begin{array}{l}\text { Published reports of } \\
\text { accurate patient-specific } \\
\text { haemodynamic simulations } \\
\text { with sufficient detail to } \\
\text { optimise CRT before } \\
\text { surgical intervention }\end{array}$ & $\begin{array}{l}\text { Improved selection of CRT } \\
\text { responders. Simulation and } \\
\text { selection of optimal tuning of } \\
\text { device settings and lead } \\
\text { placement on an individual } \\
\text { case basis }\end{array}$ & $\begin{array}{l}\text { Uncertainties and } \\
\text { assumptions regarding } \\
\text { boundary conditions and the } \\
\text { range of clinical } \\
\text { measurements required for } \\
\text { parameterisation. Mesh } \\
\text { generation, prolonged } \\
\text { computation times }\end{array}$ & \\
\hline VADs & $\begin{array}{l}\text { Generic optimisation of } \\
\text { pump design. } \\
\text { Patient-specific models can } \\
\text { aid implantation strategy } \\
\text { and tuning of output } \\
\text { according to patient } \\
\text { physiology }\end{array}$ & $\begin{array}{l}\text { Published models describing } \\
\text { haemodynamic influences of } \\
\text { catheter placement and } \\
\text { minimisation of adverse } \\
\text { haemodynamic effects }\end{array}$ & $\begin{array}{l}\text { Pump tuning to ensure } \\
\text { periodic opening and closing } \\
\text { of } \mathrm{AV} \text {, preventing leaflet } \\
\text { fusion. Personalised catheter } \\
\text { placement planning } \\
\text { (prediction and avoidance } \\
\text { stasis and thrombus } \\
\text { formation) }\end{array}$ & $\begin{array}{l}\text { Post-implantation imaging } \\
\text { artefact limits modelling. } \\
\text { Optimising performance } \\
\text { requires the balance of } \\
\text { multiple competing factors. } \\
\text { As for all cardiac } \\
\text { electromechanical models, } \\
\text { selection of appropriate } \\
\text { patient specific parameters is } \\
\text { difficult due to sparsity of } \\
\text { data }\end{array}$ & \\
\hline $\begin{array}{l}\text { Congenital heart } \\
\text { disease }\end{array}$ & $\begin{array}{l}\text { CFD simulates } \\
\text { haemodynamics which are } \\
\text { complex and hard to predict } \\
\text { in the context of a diverse } \\
\text { and heterogeneous range of } \\
\text { disease phenotypes }\end{array}$ & $\begin{array}{l}\text { Range of models described, } \\
\text { including reduced order, 3D } \\
\text { CFD, FSI and multiscale, } \\
\text { particularly in the context of } \\
\text { univentricular circulation, } \\
\text { aortic and pulmonary } \\
\text { malformations }\end{array}$ & $\begin{array}{l}\text { Modelling enables greater } \\
\text { understanding of systemic } \\
\text { and regional haemodynamics } \\
\text { and the prediction of } \\
\text { response to putative surgical } \\
\text { or device-based treatments } \\
\text { which often involve } \\
\text { significant modifications to } \\
\text { the circulatory tree }\end{array}$ & $\begin{array}{l}\text { Acquisition and application of } \\
\text { model parameters and } \\
\text { boundary conditions from } \\
\text { patient and literature data. } \\
\text { The ultimate personalisation } \\
\text { challenge }\end{array}$ & 424344 \\
\hline
\end{tabular}

AV, aortic valve; CFD, computational fluid dynamics; CRT, cardiac resynchronisation therapy; CT (A), CT (angiography); DCM, dilated cardiomyopathy; FSI, fluid solid interaction; HCM, hypertrophic cardiomyopathy; HFPEF, heart failure with preserved EF; HFREF, heart failure with reduced EF; MI, myocardial infarction; NH, neointimal hyperplasia; PAP, pulmonary artery pressure; $P C$, phase-contrast; $P C l$, percutaneous coronary intervention; RA, regulatory authority; RWMA, regional wall motion abnormality; (v)FFR; (virtual) fractional flow reserve; VAD, ventricular assist device; WSS, wall shear stress.

\section{MODEL CONSTRUCTION}

CFD model construction and solution can be described in seven stages (figure 1):

1. Clinical imaging

A range of medical imaging modalities can be used, including ultrasound, CT, MRI and X-ray angiography. Imaging must provide sufficient anatomical and physiological detail, in an appropriate format and quality, to enable segmentation and data extraction. $^{49}$

\section{Segmentation and reconstruction}

Segmentation methods convert medical images to in silico geometries which define the physical bounds of the model region of interest. If images are acquired over a cardiac cycle, anatomical motion can be tracked over segmented regions. ${ }^{50} 51$ 3. Discretisation

Spatial discretisation, or 'meshing', divides the geometry into a number of discrete volumetric elements or cells. Temporal discretisation divides the solution into discrete time steps. The accuracy and numerical stability of the analysis are influenced by both spatial and temporal refinement. The fabrication of the mesh, and the level of mesh refinement, are influenced by case- and context-specific factors. The mesh and timestep (ie, spatio-temporal discretisation) must be refined enough to capture the important haemodynamic behaviour of the modelled compartment (the final solution should be independent of mesh parameters), but without excessive refinement because this impacts negatively on computational resource and solution time (see online supplementary table S1).

\section{Boundary conditions}

Because it is impossible to discretise the entire cardiovascular system, the region to be analysed will have at least one inlet and one outlet. To enable CFD analysis, the physiological conditions at the wall and inlet/outlet boundaries must be specified. Boundary conditions are a set of applied physiological parameters (which may vary over time) that define the physical conditions at the inlets, outlets and walls. They may be based on patient-specific data, population data, physical models or assumptions. $^{39}$ 
Table 2 CFD—a glossary of selected useful terminology

\begin{tabular}{|c|c|}
\hline Analytical solution & $\begin{array}{l}\text { Relatively simple models can be described by solving a number of equations using mathematical analysis techniques such as calculus } \\
\text { or trigonometry. The solution is analytical because an exact solution can be obtained through algebraic manipulation of the equations } \\
\text { (cf. numerical solution). }\end{array}$ \\
\hline $\begin{array}{l}\text { Bernoulli equation: } \\
\mathrm{P}+(1 / 2) \rho \mathrm{V}^{2}+\rho g h=\text { constant } \\
\text { Rearranged and simplified: } \\
\Delta \mathrm{P}=(1 / 2) \rho\left(\mathrm{V}_{2}^{2}-\mathrm{V}_{1}^{2}\right)\end{array}$ & $\begin{array}{l}\text { The Bernoulli equation relates blood pressure }(P) \text { and flow velocity }(V \text {. The total energy of flowing blood comprises hydrostatic }(P) \text {, } \\
\text { kinetic }\left((1 / 2) \rho V^{2}\right) \text { and potential ( } \rho g \text { where } \rho \text { is fluid density, } g \text { is gravity and } h \text { is height) energies, the sum of which is conserved. } \\
\text { Therefore, an increase in flow velocity must be accompanied by a decrease in pressure, and vice versa. Gravitational effects ( } \rho g h) \text { are } \\
\text { usually neglected in a supine vessel. The simplified and rearranged equation is used routinely to calculate transvalvular pressure } \\
\text { gradients from flow velocity. The Bernoulli equation ignores energy loss due to viscous friction (see Poiseuille equation) and } \\
\text { turbulence, and assumes steady flow. }\end{array}$ \\
\hline Boundary conditions & $\begin{array}{l}\text { A set of parameters or relationships which describe the physiological conditions (haemodynamic or structural) acting at the boundaries } \\
\text { of a modelled segment, representing the interaction of the model with its distal compartments. }\end{array}$ \\
\hline Discretisation & To divide into discrete elements or time periods. \\
\hline Electrical analogue & $\begin{array}{l}\text { An electrical circuit design used to represent a compartment of the circulation, using, for example, 'voltages' (pressures), 'current' } \\
\text { (flow) and resistors. They lack spatial dimensions and are therefore also referred to as dimensionless or 'zero- } D \text { ' (OD) models. }\end{array}$ \\
\hline In silico & 'Represented or simulated in a computer', comparable to in vivo and in vitro. \\
\hline Multi-scale model & A model which integrates models of different length- and or time-scales. \\
\hline $\begin{array}{l}\text { Newtonian and non-Newtonian } \\
\text { fluid }\end{array}$ & $\begin{array}{l}\text { As blood is a suspension, non-Newtonian behaviour is particularly important within the capillaries where the size of (solid) blood cells } \\
\text { is large relative to vessel calibre, resulting in a non-linear relationship between shear-stress and viscosity. In larger blood vessels } \\
\text { Newtonian fluid behaviour is often assumed whereby viscosity is constant, independent of the shear-stress acting on the fluid. }\end{array}$ \\
\hline Numerical solution & $\begin{array}{l}\text { In more complex models the mathematics becomes too complicated for analytical techniques and numerical techniques are used } \\
\text { instead. Rather than generating an exact solution, the result is an approximation, albeit within very close bounds under certain } \\
\text { circumstances. Typically, iterative methods are employed to produce a solution to the equations that converges around the true values. } \\
\text { Used to resolve complicated, non-linear, transient (time-varying) analyses for example, 3D-CFD models. }\end{array}$ \\
\hline $\begin{array}{l}\text { Poiseuille equation: } \\
\mathrm{Q}=\frac{\Delta \mathrm{P} \pi \mathrm{r}^{4}}{8 \mu \mathrm{L}}\end{array}$ & $\begin{array}{l}\text { The Poiseuille equation describes blood flow }(\mathrm{Q}) \text {, along a vessel in relation to viscosity }(\mu) \text {, vessel geometry (length }(L) \text { and radius }(r) \text { ) } \\
\text { and the driving pressure gradient }(\Delta P) \text {. According to Poiseuille, flow is strongly dependent upon vessel radius (fourth power). } \\
\text { Poisuille's equation considers viscous (frictional) energy losses. }\end{array}$ \\
\hline \multicolumn{2}{|l|}{ Rearranged: } \\
\hline \multicolumn{2}{|l|}{$\Delta \mathrm{P}=\frac{8 \mu \mathrm{LQ}}{\pi \mathrm{r}^{4}}$} \\
\hline Segmentation & The process by which relevant structures in medical images are identified, isolated and converted into computer representations. \\
\hline Windkessel & $\begin{array}{l}\text { German for 'air-chamber'. Windkessel models are relatively simple zero-D models used to represent the resistive and compliant } \\
\text { properties of the arterial vasculature. }\end{array}$ \\
\hline Workflow & $\begin{array}{l}\text { A sequence of applications (computational tools) which are executed sequentially to manipulate medical data to build a model and } \\
\text { perform computational analyses. Typically this involves medical imaging, segmentation, discretisation, CFD simulation and } \\
\text { post-processing, that is, from clinical imaging to results. Sometimes referred to as a tool-chain. }\end{array}$ \\
\hline
\end{tabular}

CFD, computational fluid dynamics.

\section{Simulation}

A computer file defining the physical parameters of the model is written. In addition to the geometric, discretisation and boundary data, this file must define properties including: blood density and viscosity (ie, the fluid model), the initial conditions of the system (eg, whether the fluid is initially static or moving), time discretisation information (time step size and numerical approximation schemes), and the desired output data (eg, number of cardiac cycles to be simulated). This information allows the CFD solver to solve the Navier-Stokes and continuity equations, proceeding incrementally towards a final solution ('convergence'). A typical 3D cardiovascular simulation involves $>1$ million elements run over several cardiac cycles, each divided into hundreds or thousands of individual time-steps. Millions of non-linear partial differential equations are solved simultaneously, and repeatedly, over all elements, at all timesteps. 3D CFD modelling is therefore time-consuming and computationally demanding.

6. Post-processing

Typically, the CFD solver produces the pressure and velocity field over all elements at each time-step. Only a small proportion of these data are of interest to the operator, so some postprocessing is required to extract and display relevant data. ${ }^{18}$

7. Validation

It is important that modelled results are validated against an acceptable standard. Commonly, this involves comparison with either values measured within an in vitro phantom or acquired during in vivo assessment. ${ }^{4}$ Validation generates confidence in the accuracy and reliability of a CFD model.

\section{THE WORKFLOW}

Collectively, the steps outlined above are known as a workflow or toolchain (see figure 1 and online supplementary video). Although there are many specialised software applications facilitating the construction and operation of CFD-based workflows, considerable skill and experience are required at each stage (especially steps 3-5) to ensure reliability of results. ${ }^{49}$

\section{ADVANCED BOUNDARY CONDITIONS}

Rather than specifying pressure or flow at a boundary, an additional, lower-order model may be coupled to the 3D solver to generate more realistic conditions proximal and distal to the simulation domain (see table 1 and figure 2). This method of modelling is efficient, because it allows detailed analysis in the $3 \mathrm{D}$ region without wasting high temporal and spatial refinement on regions beyond this. In some cases the model representing the distal boundary also provides proximal boundary condition. These closed-loop models, or system models, require very careful tuning. ${ }^{52}$

\section{ASSUMPTIONS}

Many CFD models assume that the segmented region has rigid walls. Although untrue in the cardiovascular system, this 
Table 3 A summary of the various orders of CFD modelling applied to the cardiovascular system

\begin{tabular}{|c|c|c|c|c|}
\hline Model & Figure & CFD solution & Description/examples & $\begin{array}{l}\text { Typical solution } \\
\text { time }^{+}\end{array}$ \\
\hline OD & & $\begin{array}{l}\text { No spatial dimension. Physiological } \\
\text { variables such as pressure }(P), \text { flow }(Q) \\
\text { and resistance }(R) \text { are assumed } \\
\text { spatially uniform within the model, } \\
\text { varying only as a function of time }(t), \\
\text { eg, } \\
P_{(t)}=Q_{(t)} \cdot R_{(t)} \\
\text { Solved with ordinary differential (OD } \\
\text { NS) equations }\end{array}$ & $\begin{array}{l}\text { Lump together distributed physiological systems } \\
\text { into a single description. They describe the global } \\
\text { behaviour of the modelled segment. The } 0 \mathrm{D} \\
\text { Windkessel model (pictured) is often used to } \\
\text { represent the compliant and resistive nature of } \\
\text { the arterial circulation. OD models are frequently } \\
\text { used to model components of the cardiovascular } \\
\text { system or to improve boundary conditions for 3D } \\
\text { models of arterial, ventricular or venous } \\
\text { pathophysiology. }{ }^{5} 47\end{array}$ & Immediate solution \\
\hline 1D & & $\begin{array}{l}\text { Physiological variables are solved as a } \\
\text { function of a single spatial variable, } \\
\text { typically length }(x), \text { eg, } \\
P_{(x, t)}=Q_{(x, t)} \cdot R_{(x, t)} \\
\text { Solved with partial differential (1D NS) } \\
\text { equations }\end{array}$ & $\begin{array}{l}\text { Used to represent wave propagation } \\
\text { characteristics and wave reflection. 1D models } \\
\text { may also be used to provide boundary conditions } \\
\text { for higher order models in order to increase } \\
\text { refinement of the solution, especially where the } \\
\text { effects of wave reflection are significant. }{ }^{45} 46\end{array}$ & $\begin{array}{l}\text { S (static) } \\
\text { Min (transient) }\end{array}$ \\
\hline 2D & & $\begin{array}{l}\text { Physiological variables are solved as a } \\
\text { function of two spatial variables, } \\
\text { typically length and distance from } \\
\text { centreline }(r) \text { eg, } \\
P_{(x, r, t)}=Q_{(x, r, t)} \cdot R_{(x, r, t)} \\
\text { Solved with axisymmetric NS } \\
\text { equations }\end{array}$ & $\begin{array}{l}\text { Able to resolve the solution in } 2 \mathrm{D} \text {. Used less } \\
\text { often now than previously due to ready } \\
\text { availability of improved computer processing and } \\
\text { 3D solvers. Examples include the simulation of } \\
\text { para-prosthetic valve haemolysis and } \\
\text { improvement of the assessment of the proximal } \\
\text { flow convergence zone in the clinical evaluation } \\
\text { of regurgitant valve disease. }\end{array}$ & \\
\hline $3 \mathrm{D}$ & & $\begin{array}{l}\text { Physiological variables are solved as a } \\
\text { function of all three spatial variables, } \\
\text { including the angle around the } \\
\text { centreline axis }(\theta) \text { eg, } \\
P_{(x, r, \theta, t)}=Q_{(x, r, \theta, t)} \cdot R_{(x, r, \theta, t)} \\
\text { Solved with full 3-D NS equations }\end{array}$ & $\begin{array}{l}\text { Full 3D CFD can resolve the physiological solution } \\
\text { in all dimensions including time. Examples are } \\
\text { more widely reviewed in the main body of the } \\
\text { text. }\end{array}$ & $\begin{array}{l}\text { Order of minutes for } \\
\text { steady- state } \\
\text { Order of hours or } \\
\text { days for transient }\end{array}$ \\
\hline
\end{tabular}

*Hydro-electrical analogue diagrams are often used to describe physiological components such as resistance, pressure (voltage), compliance (capacitance), and flow (current). tSolution times vary according to complexity of the model and the mathematical solution. The times presented are approximate and are based on a model of coronary physiology. ${ }^{5}$ CFD, computational fluid dynamics; NS, Navier-Stokes; OD, zero dimensional; 1D, one dimensional; 2D, two dimensional; 3D, three dimensional.

approximation is acceptable for some applications. ${ }^{53}$ Vessel compliance allows blood to be stored during systole and released during diastole. At the system level this results in a finite speed of pressure wave transmission and tends to reduce the peak pressures associated with the inertial acceleration of the blood. Compliance tends to reduce shear stresses because the vessels are slightly larger when peak flow occurs. It is possible to model deformation of the wall, due to cardiac and respiratory variation, in response to change in pressure using fluid-solid interaction (FSI) models. These are far more complex to solve, boundary conditions are a challenge, and many wall parameters remain unknown, which increases the number of assumptions. Furthermore, it is yet to be established for which applications a full FSI approach improves accuracy. An example of the increased computational cost of FSI is reported by Brown et $\mathrm{al}^{54}$ where $3 \mathrm{D}$ transient (time-varying) analysis of the aorta required $145 \mathrm{~h}$ (FSI) compared with $6.6 \mathrm{~h}$ (CFD). An alternative is to impose wall movement derived from imaging data (eg, gated MRI). There are exciting developments in the use of data assimilation techniques in which sparse clinical data, for example, from 4D imaging, are integrated with the analysis process so that material properties of tissues in individual patients are recovered as the simulation progresses. ${ }^{55}$ In biomedical workflows it is assumed the boundaries of the fluid geometry are smooth, yet medical images may not generate smooth surfaces due to poor resolution or imaging artefacts. Instead, structures may be smoothed in silico after segmentation.
Typically, cardiovascular simulations assume blood behaves as an incompressible fluid. Although blood exhibits non-Newtonian behaviour (see glossary in table 2), which must be simulated for flow in small capillaries, in larger vessels these effects are often neglected and a Newtonian fluid model is assumed.

\section{BENEFITS OF CARDIOVASCULAR CFD MODELLING}

CFD modelling enables investigation of pressure and flow fields at a temporal and spatial resolution unachievable by any clinical methodology. Post-processing provides additional data, generating new insights into physiology and disease processes. For example, it is difficult, and invasive, to measure arterial wall shear stress (WSS), a key factor in the development of atherosclerosis and in-stent restenosis, whereas CFD models can compute WSS and map its spatial distribution. ${ }^{20} 21$ Such work has established the link between haemodynamic disturbance and atherogenesis and has explained the preferential deposition of atherosclerotic plaque at arterial bends and bifurcation regions. $^{22}$ CFD modelling has been central to our current understanding of the effects of WSS on endothelial homeostasis: laminar, non-disturbed blood flow is associated with increased WSS which inhibits unnecessary endothelial cell activation; whereas turbulent or disturbed blood flow reduces WSS which stimulates adverse vessel remodelling. A complex series of WSS-related signalling pathways and interactions underlie this phenomenon. Before these pathways can be exploited to generate anti-atherosclerotic therapies their complexity needs to be 
Figure 1 Examples of aortic (A) and coronary (B) in silico computational fluid dynamics (CFD) workflows. (A) The aorta is identified from thoracic MRI (a), segmented and reconstructed (central image). A volumetric mesh is fabricated to fit the patient-specific geometry, shown in detail in panel (b). Accurate flow measurements are extracted from phase-contrast MRI data to inform the boundary conditions applied for CFD simulation, such as the inlet (c). The results are

post-processed, details of the flow field are shown in panel (d). OD models are coupled at the outlets so physiologically feasible flow-pressure relationships are computed at the outlets (e). These can be validated against other measurements, which in a preclinical scenario may be invasive. (B) (and accompanying online video) A coronary angiogram (a) is segmented (b) and reconstructed into a $3 \mathrm{D}$ in silico model. A surface and volumetric are fabricated to fit the patient-specific geometry (c). Physiological parameters such as pressure and flow are used to inform the boundary conditions applied for CFD simulation (d). The results (here pressure and flow) are post-processed and useful physiological data are extracted (e). In the preclinical, research setting simulated results are validated against an appropriate standard, for example, invasively measured values ( $f$ ). (Additional information for video legend): VIRTUheart is an academic project at the University of Sheffield funded by research grants (see virtuheart.com).
A

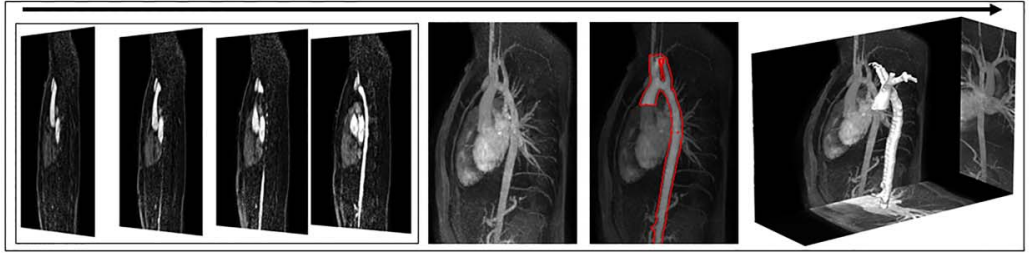

(a)
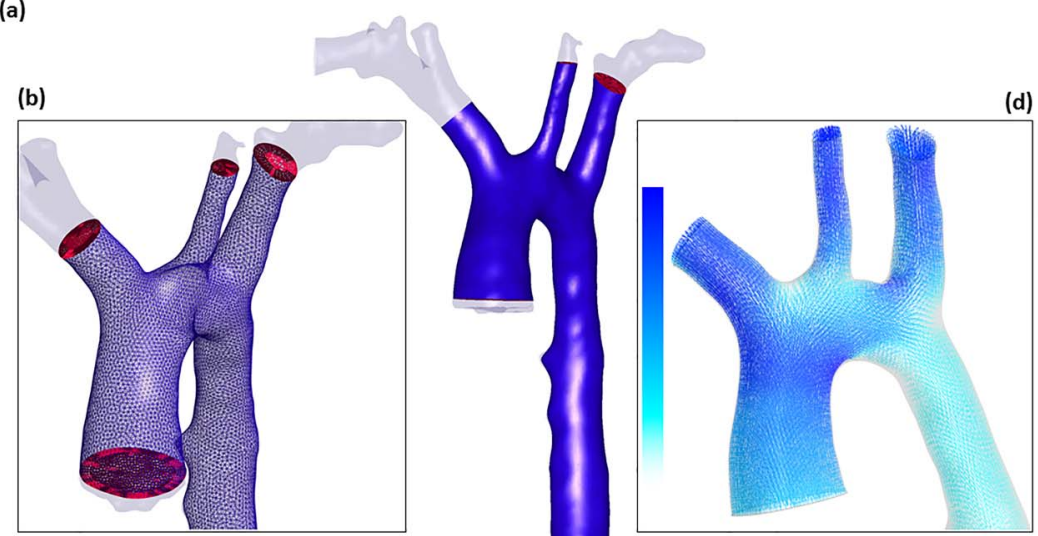

(c)



(e)

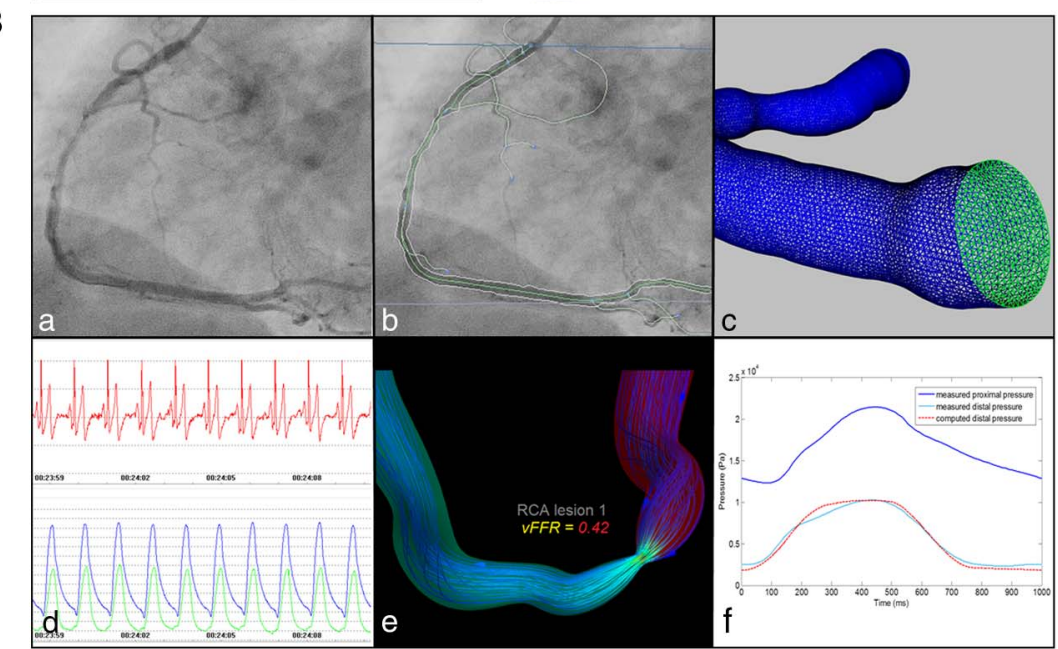

better understood. Integrated multiscale CFD models provide a powerful tool to combine analysis of fluid mechanics and cellular response. ${ }^{23}$ Recently, the effect of disturbed WSS in stented vessels has been modelled to investigate the influence on both endothelial function and neointimal hyperplasia, which preferentially accumulates at regions of low and disturbed WSS (figure 3). ${ }^{26}$ Such models can be used to develop stents which minimise the risk of in-stent restenosis and thrombosis. ${ }^{24} 25$

\section{Device design}

In silico methods allow rapid prototyping, with reduced risk to humans, so a priority for the medical devices industry is to replace expensive and time-consuming in vivo and in vitro experimentation with in silico testing. In recognition of this, the US Food and Drug Administration (FDA) issued draft guidance in 2014 on the use of modelling to support regulatory submissions. ${ }^{56}$ An example is the significant role which CFD plays in 


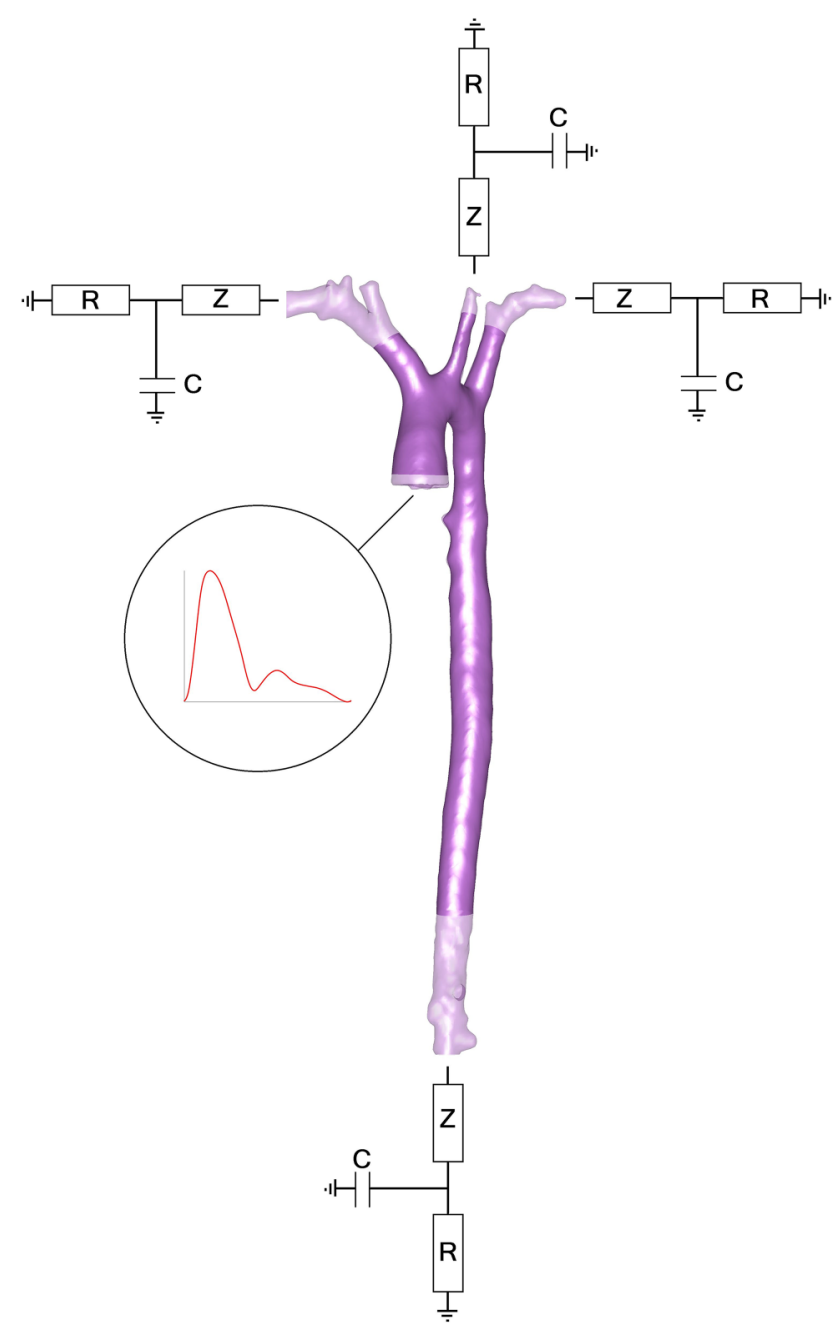

Figure 2 A patient-specific 3D computational fluid dynamics model of an aorta. Patient-specific pressure is the proximal boundary condition. Each outlet (distal boundary) is coupled to a zero-dimensional model. The zero-dimensional models represent the impedance (Z), resistance (R) and compliance/capacitance $(C)$ of the circulation distal to the boundaries. Output data from the 3D domain provide input to the $O D$ model and vice versa. The algebraically coded OD models compute parameters which are returned back to dynamically inform the 3D simulation. An alternative would be to couple a 1D wave transmission model at the outlets which may provide higher fidelity simulation results, especially in the aorta where the physiology is influenced by wave reflections.

design optimisation of mechanical heart valves. ${ }^{11}$ While comparison of major flow features captured in vitro with predictions from CFD shows good agreement, simulation delivers 3D information at much higher resolution within critical regions (eg, the hinges) than flow visualisation, giving invaluable insight into design-related thrombogenic potential. ${ }^{10}$ Comprehensive simulation of heart valve mechanics, including the separation of the upstream and downstream fluid regions at closure and the structural instability and snap-through dynamics of tissue valves, remain computationally challenging but achievable. ${ }^{9} 13$

CFD has been used in the optimisation of several commercial ventricular assist devices (VADs), investigating potential thrombogenicity by highlighting design-related regions of stasis and device characteristics resulting in high shear stress. ${ }^{41} \mathrm{~A}$ tool for optimising thromboresistance has been recently demonstrated in a comparative study of two continuous flow VADs, which combines experimental and numerical simulation. ${ }^{40} 57$ Numerical models can also contribute to the process of VAD implantation, informing the choice of catheter implantation site. $^{39}$

In the context of stent design, the greatest emphasis has been on modelling the mechanical integrity of the stent structure during and after deployment. However, CFD provides a valuable tool to assess the resulting haemodynamics within the stented lesion. ${ }^{26}$ This, in turn, has been associated with the biological response of the vessel wall and the development of restenosis. $^{27}$

\section{Diagnostic tools and personalised medicine}

Computing intravascular physiology, with the aim of minimising invasive instrumentation, is of major interest. A prime example is fractional flow reserve (FFR), an index of physiological (coronary atherosclerosis) lesion significance, measured with a pressure-sensitive angioplasty guidewire. FFR-guided therapy improves patient outcomes, reduces stent insertions, and reduces costs, yet it is used in $<10 \%$ of cases due to a host of procedural and operator related factors. ${ }^{58}$ Several groups propose models for computing 'virtual' FFR from angiography to provide the benefits of physiological assessment without the practical drawbacks which limit the invasive technique (see online supplementary figure S1). ${ }^{5} 6759$ The VIRTU-1 trial demonstrated the effectiveness of CFD-derived FFR using invasive angiography (diagnostic accuracy $97 \%$ vs invasive FFR). ${ }^{5}$ More recently, the HeartFlow-NXT trial demonstrated the performance of virtual FFR using CT coronary angiography (sensitivity $86 \%$, specificity $79 \%$ vs invasive FFR). ${ }^{6}$ Both models offer a less invasive approach, neither requires hyperaemic flow induction nor the passage of an intracoronary wire, and taken together could offer the benefits of FFR to all patients being assessed for coronary artery disease (CAD). ${ }_{C T}$ FFR (HeartFlow Inc) is now FDA approved for use as a class II Coronary Physiologic Simulation Software Device. ${ }^{60}$

Recent in vitro work combining CFD, colour Doppler and simulated Doppler images demonstrates the potential to reduce Doppler inter-user variability and inform interpretation of complex regurgitant flow fields in valvular heart disease. ${ }^{61}$ In silico models of the right heart and pulmonary arteries using phase-contrast MRI capture anatomical and flow velocity data to simulate pulmonary artery physiology. ${ }^{62}$ It is hoped that these models will soon deliver a diagnosis of pulmonary hypertension without invasive catheterisation. ${ }^{31}$ Added value may come from wave analysis of these models to discriminate between the key aetiological sub-groups of pulmonary hypertension. ${ }^{30}$

Treatment decisions are often based upon the 'gold standard' of randomised controlled trials. Everyday clinical practice, however, requires tailored treatment for individual patients. CFD modelling offers a patient-specific approach to management, in which an individual's unique anatomy and physiology are used to define the model. The impact of alternative interventional strategies can be compared and a personalised, optimised strategy selected. ${ }^{63}$ Patient-specific modelling will not diminish the need for clinical trials but will allow the delivery of truly objective, personalised management on a wide scale.

This approach is exemplified in aortic aneurysm management, where current simplistic guidelines use aneurysm diameter as the arbiter of treatment. The @ neurIST project addresses this, and incorporates patient-specific anatomic, genomic and demographic data, with simulated flow patterns (figure 4), to calculate the risk of rupture. ${ }^{64}$ The optimal treatment of aortic type B 
A

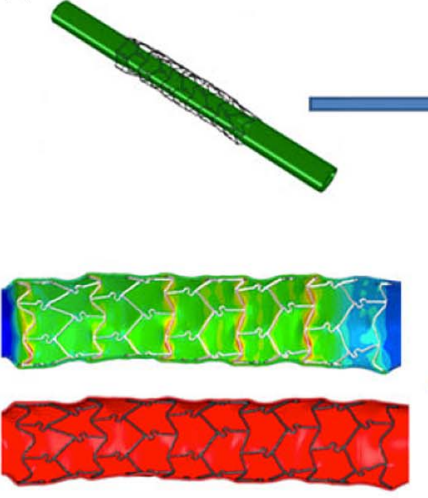

C

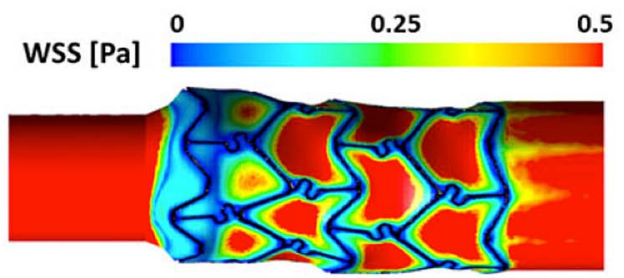

B
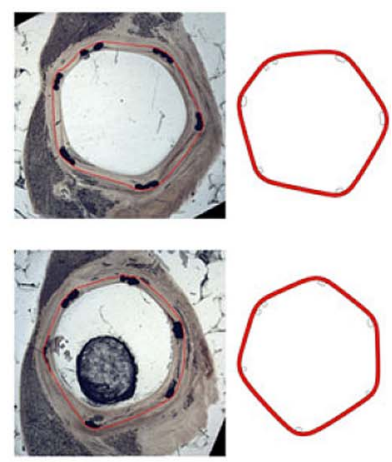

D

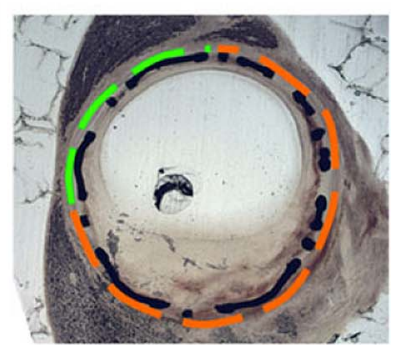

Figure 3 A computational fluid dynamics (CFD) model demonstrating the correlation between wall shear stress (WSS) and restenosis in coronary artery disease. (A) Structural modelling of stent insertion in porcine coronary arteries reconstructed from micro-CT, and stent-artery coupling obtained after arterial recoil. (B) Comparison between the in vivo histological images (left) and corresponding sections from the structural simulation (right) demonstrating excellent agreement. (C) Results of the CFD simulations in terms of the spatial distribution of WSS magnitude over the arterial wall. (D) The correlation between areas characterised by low WSS (orange lines) and in-stent restenosis after 14 days. The CFD simulation of WSS has identified areas of reduced shear and restenosis with excellent agreement. Figure reproduced from Morlacchi et al ${ }^{26}$ with kind permission from Springer Science and Business Media.

dissections remains controversial. Thoracic endovascular aortic repair (TEVAR) carries a risk of spinal ischaemia, and multiple communicating channels between true and false lumens confer a risk of proximal rupture if only the primary entry is closed. Therefore, graft length is balanced against the risk of paraplegia. In this context, CFD modelling provides individualised risk stratification and optimised treatment delivery (figure 5). ${ }^{65} 18$ Similar simulations are useful in the context of abdominal aortic aneurysm. ${ }^{66} 67$

\section{FULL SYSTEM MODELS: THE VIRTUAL PHYSIOLOGICAL HUMAN}

There is increasing interest in integrating multiple physiological models into comprehensive system models to simulate the impact of various conditions, pathologies and treatments across multiple organ systems. While this is ambitious, large, international, collaborative research projects under the umbrella of the Virtual Physiological Human (VPH) reflect the seriousness, legitimacy and rationale underlying this long-term vision. ${ }^{68}$ Full system models offer the possibility of understanding, holistically, the impact of cardiovascular disease upon individual patients.

\section{IN SILICO TRIALS}

In silico techniques can simulate measures of safety, accuracy, and efficacy of interventions, both pharmacological and mechanical, in large cohorts of virtual patient models which represent naturally occurring physiological and pathological variability. This minimises the time, cost, and risk associated with clinical

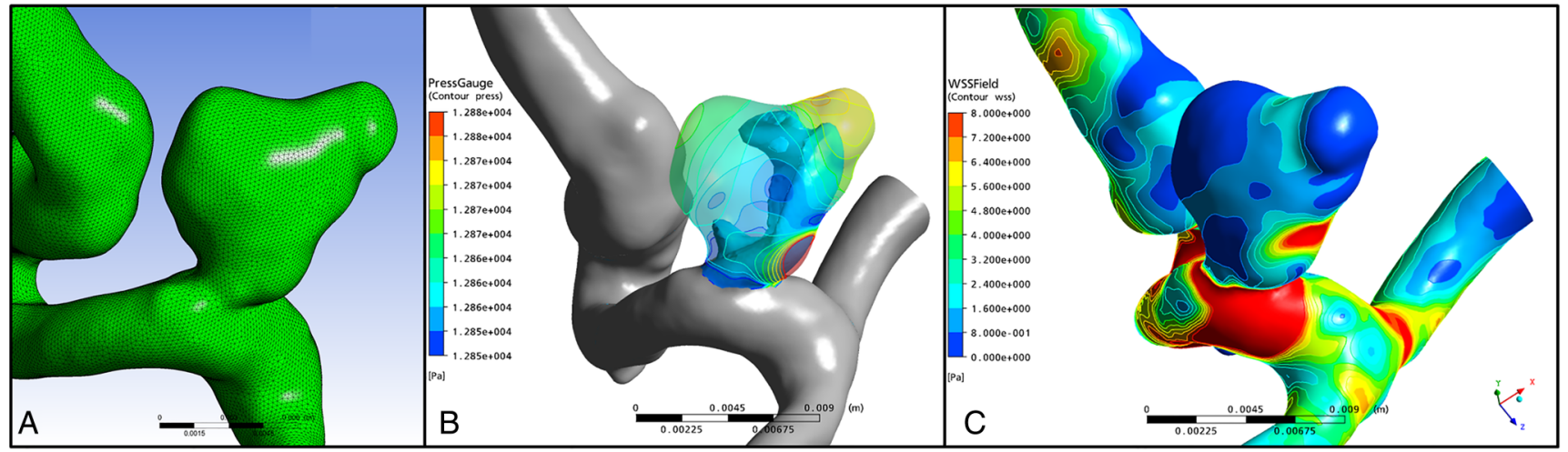

Figure 4 Computational fluid dynamics (CFD) model of an intracranial berry aneurysm from the @neurist project. Panel (A) demonstrates the reconstructed surface mesh. Panels (B) and (C) demonstrate the CFD simulated pressure (B) and wall shear stress (C) acting upon the aneurysm wall, which may be useful in predicting risk of rupture on a patient-specific basis. 


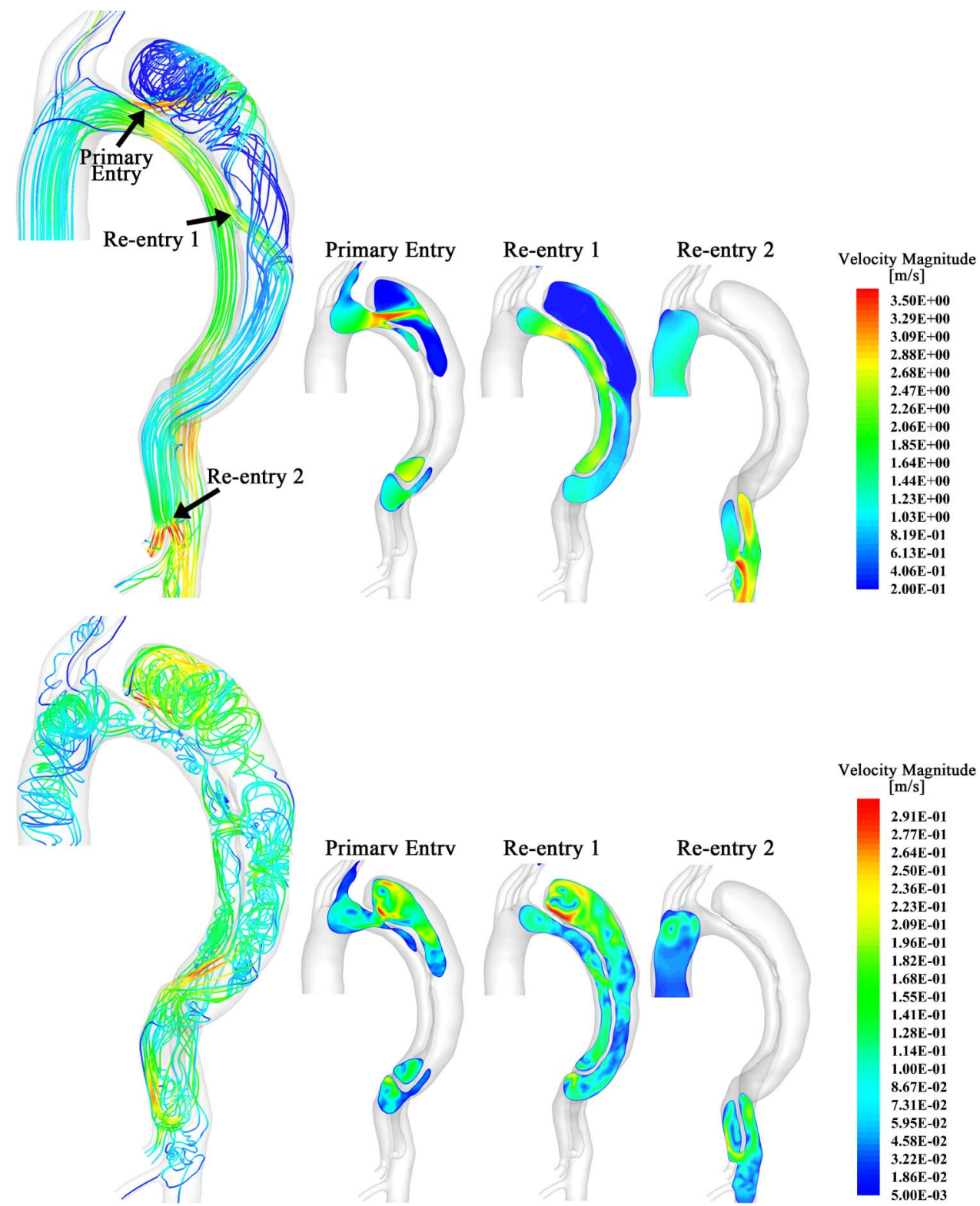

Figure 5 Segmentation, reconstruction and 3D simulation of a chronic type B aortic dissection with true and false lumen in systole (top row) and diastole (bottom row). The primary entry point (top arrow) is close to the left subclavian artery. Two more communications ('re-entries') are seen distally. Computational fluid dynamics simulation allows the flow through each re-entry point to be studied separately in order to predict response to intervention. During systole simulation demonstrates high blood flow velocity through the primary entry point. However, simulation predicts significant flow through the first re-entry point in systole, and even higher during diastole, thus demonstrating that closure of the primary entry point alone will not be sufficient to induce false lumen thrombosis and avoid further expansion. Reproduced with permission from Chen et al, 2013. ${ }^{18}$

trials. The Avicenna project leverages significant commercial interest and engagement to develop a 'roadmap' describing the route by which multi-scale in silico techniques can achieve this. 69

\section{CHALLENGES AND LIMITATIONS}

CFD models in medicine have traditionally been used by two user groups: industrial medical device developers, in rapid, low-cost, device prototyping; and academics, to investigate cardiovascular physiology and compute parameters that cannot otherwise be obtained. Both groups construct models which are typically complex, involve multiple finely-tuned geometric, haemodynamic and material parameters and require long computation times. In contrast, clinicians are a third, emerging user group, who require rapid results with adequate accuracy.
Model accuracy is determined by model design and quality of input data. For CFD applications it is unclear how detailed the clinical data needs to be in terms of geometry (segmented from medical images) and parameterisation (variability described by the model and the tuning of patient-specific boundary conditions). Continuing improvements in imaging, image-registration and segmentation algorithms will augment accuracy. ${ }^{50}$ Model parameterisation is more challenging, because it requires detailed knowledge of physiological metrics in the proximal and distal circulations which may be inaccessible and variable in health and in disease, for example, microcirculatory resistance is a major determinant of coronary blood flow. Further understanding of the relative importance of physiological parameters is required to determine those which are most influential, and those which can be assumed or averaged. ${ }^{70}$ This allows 
unnecessary model complexity to be simplified, balancing computing speed against accuracy. ${ }^{54} \mathrm{~A}$ second challenge is the development of relevant industry standards. In the European Union and USA, diagnostic software is regulated via CE marking and FDA directives, respectively; but there are no industry standards governing accuracy, reliability or validation. The FDA is addressing this through benchmarking initiatives, in the same way that aviation authorities adopted computer-aided design over traditional physical testing. ${ }^{71}$ Third, large volumes of clinical data, of value for model development and validation, are stored in hospital systems. Access is variable and restrictive; although the VPH-Share project demonstrates how anonymised patientspecific data and in silico models can be shared securely. ${ }^{72}$ Access to such data supports model validation against long-term outcomes which may expedite clinical translation. Fourth, CFD modelling can be perceived as a 'disruptive technology', and a threat, especially by manufacturers of traditional hardware. Finally, the next generation of doctors will require training in in silico systems, and understanding their principles, methodologies and limitations. Several initiatives are attempting to address this, but in the longer term, in silico medicine may gain prominence in medical curricula. ${ }^{6873} 74$

\section{FUTURE DIRECTIONS}

In the context of device development, the major computational modelling and technological challenges have already been addressed and the benefits of simulation are recognised by the regulatory authorities. Sustained investment will enable engineers to continue model refinement and the development of novel applications, specifically targeting increases in precision, personalisation and speed. Beyond technological development, and before these tools become established in routine clinical practice, the most immediate need is to demonstrate equivalence of in silico results relative to invasive measurements through observational trials. Beyond this, efficacy must be demonstrated in large multicentre clinical trials. It is clear that these techniques have the potential to change clinical practice. The beneficiaries will be patients, clinicians and healthcare providers.

\section{Acknowledgements Dr Morris is funded by a Clinical Research Training Fellowship from the British Heart Foundation. Figure 4 was kindly provided by Dr Alberto Marzo, University of Sheffield.}

Contributors All authors have made a substantial contribution to the conception or design of the work, the drafting and revision of the work and have made an intellectual contribution. All authors have given final approval of the version submitted and have agreed to be accountable for all aspects of the work.

Funding British Heart Foundation (R/134747-11-1).

Competing interests None declared.

Provenance and peer review Not commissioned; externally peer reviewed.

Open Access This is an Open Access article distributed in accordance with the terms of the Creative Commons Attribution (CC BY 4.0) license, which permits others to distribute, remix, adapt and build upon this work, for commercial use, provided the original work is properly cited. See: http://creativecommons.org/ licenses/by/4.0/

\section{REFERENCES}

1 Taylor CA, Figueroa CA. Patient-specific modeling of cardiovascular mechanics. Annu Rev Biomed Eng 2009;11:109-34.

2 Smith N, de Vecchi A, McCormick M, et al. euHeart: personalized and integrated cardiac care using patient-specific cardiovascular modelling. Interface Focus 2011:1:349-64.

3 Gasser TC, Nchimi A, Swedenborg J, et al. A novel strategy to translate the biomechanical rupture risk of abdominal aortic aneurysms to their equivalent diameter risk: method and retrospective validation. Eur J Vasc Endovasc Surg 2014;47:288-95
4 Radaelli AG, Augsburger L, Cebral JR, et al. Reproducibility of haemodynamical simulations in a subject-specific stented aneurysm model-a report on the Virtual Intracranial Stenting Challenge 2007. J Biomech 2008;41:2069-81.

5 Morris PD, Ryan D, Morton AC, et al. Virtual fractional flow reserve from coronary angiography: modeling the significance of coronary lesions: results from the VIRTU-1 (VIRTUal Fractional Flow Reserve From Coronary Angiography) Study. JACC Cardiovasc Interv 2013;6:149-57.

6 Nørgaard BL, Leipsic J, Gaur S, et al. Diagnostic performance of noninvasive fractional flow reserve derived from coronary computed tomography angiography in suspected coronary artery disease: the NXT trial (Analysis of Coronary Blood Flow Using CT Angiography: Next Steps). J Am Coll Cardiol 2014;63:1145-55.

7 Tu S, Barbato E, Køszegi Z, et al. Fractional flow reserve calculation from 3-dimensional quantitative coronary angiography and TIMI frame count: a fast computer model to quantify the functional significance of moderately obstructed coronary arteries. JACC Cardiovasc Interv 2014;7:768-77.

8 Morris PD, van de Vosse FN, Lawford PV, et al. "Virtual" (computed) fractional flow reserve: current challenges and limitations. JACC Cardiovasc Interv 2015;8:1009-17

9 Sotiropoulos F, Borazjani I. A review of state-of-the-art numerical methods for simulating flow through mechanical heart valves. Med Biol Eng Comput 2009;47:245-56

10 Simon HA, Ge L, Borazjani I, et al. Simulation of the three-dimensional hinge flow fields of a bileaflet mechanical heart valve under aortic conditions. Ann Biomed Eng 2010;38:841-53.

11 Yoganathan AP, Chandran KB, Sotiropoulos F. Flow in prosthetic heart valves: state-of-the-art and future directions. Ann Biomed Eng 2005;33:1689-94.

12 Astorino M, Hamers J, Shadden SC, et al. A robust and efficient valve model based on resistive immersed surfaces. Int J Numer Method Biomed Eng 2012;28:937-59.

13 De Hart J, Peters GW, Schreurs PJ, et al. A three-dimensional computational analysis of fluid-structure interaction in the aortic valve. J Biomech 2003;36:103-12

14 Erhart P, Hyhlik-Dürr A, Geisbüsch P, et al. Finite element analysis in asymptomatic, symptomatic, and ruptured abdominal aortic aneurysms: in search of new rupture risk predictors. Eur J Vasc Endovasc Surg 2015;49:239-45.

15 Georgakarakos E, Ioannou CV, Papaharilaou Y, et al. Computational evaluation of aortic aneurysm rupture risk: what have we learned so far? J Endovasc Ther 2011;18:214-25.

16 Molony DS, Kavanagh EG, Madhavan P, et al. A computational study of the magnitude and direction of migration forces in patient-specific abdominal aortic aneurysm stent-grafts. Eur J Vasc Endovasc Surg 2010;40:332-9.

17 Karmonik C, Müller-Eschner M, Partovi S, et al. Computational fluid dynamics investigation of chronic aortic dissection hemodynamics versus normal aorta. Vasc Endovascular Surg 2013;47:625-31.

18 Chen D, Müller-Eschner M, von Tengg-Kobligk H, et al. A patient-specific study of type-B aortic dissection: evaluation of true-false lumen blood exchange. Biomed Eng Online 2013;12:65.

19 Cheng Z, Juli C, Wood NB, et al. Predicting flow in aortic dissection: comparison of computational model with PC-MRI velocity measurements. Med Eng Phys 2014;36:1176-84.

20 Chien S. Mechanotransduction and endothelial cell homeostasis: the wisdom of the cell. Am J Physiol Heart Circ Physiol 2007;292:H1209-24.

21 LaDisa JF, Jr., Olson LE, Molthen RC, et al. Alterations in wall shear stress predict sites of neointimal hyperplasia after stent implantation in rabbit iliac arteries. Am J Physiol Heart Circ Physiol 2005;288:H2465-75.

22 Jin S, Yang Y, Oshinski J, et al. Flow patterns and wall shear stress distributions at atherosclerotic-prone sites in a human left coronary artery -an exploration using combined methods of CT and computational fluid dynamics. Conf Proc IEEE Eng Med Biol Soc 2004;5:3789-91.

23 Lee J, Smith NP. The multi-scale modelling of coronary blood flow. Ann Biomed Eng 2012;40:2399-413.

24 Jiménez JM, Davies PF. Hemodynamically driven stent strut design. Ann Biomed Eng 2009;37:1483-94.

25 Seshadhri S, Janiga G, Beuing 0, et al. Impact of stents and flow diverters on hemodynamics in idealized aneurysm models. J Biomech Eng 2011;133:071005.

26 Morlacchi S, Migliavacca F. Modeling stented coronary arteries: where we are, where to go. Ann Biomed Eng 2013:41:1428-44.

27 Wentzel JJ, Krams R, Schuurbiers JC, et al. Relationship between neointimal thickness and shear stress after Wallstent implantation in human coronary arteries. Circulation 2001;103:1740-5.

28 Peach TW, Ngoepe M, Spranger K, et al. Personalizing flow-diverter intervention for cerebral aneurysms: from computational hemodynamics to biochemical modeling. Int J Numer Method Biomed Eng 2014;30:1387-407.

29 Schneiders JJ, Marquering HA, van Ooij P, et al. Additional value of intra-aneurysmal hemodynamics in discriminating ruptured versus unruptured intracranial aneurysms. AJNR Am J Neuroradiol 2015;10:1920-6.

30 Qureshi MU, Vaughan GA, Sainsbury C, et al. Numerical simulation of blood flow and pressure drop in the pulmonary arterial and venous circulation. Biomech Model Mechanobiol 2014;13:1137-54. 
31 Lungu A, Wild JM, Capener D, et al. MRI model-based non-invasive differential diagnosis in pulmonary hypertension. J Biomech 2014;47:2941-7.

32 Tang BT, Pickard SS, Chan FP, et al. Wall shear stress is decreased in the pulmonary arteries of patients with pulmonary arterial hypertension: an image-based, computational fluid dynamics study. Pulm Circ 2012;2:470-6.

33 Kheyfets VO, Rios L, Smith T, et al. Patient-specific computational modeling of blood flow in the pulmonary arterial circulation. Comput Methods Programs Biomed 2015;120:88-101.

34 Niederer SA, Plank G, Chinchapatnam P, et al. Length-dependent tension in the failing heart and the efficacy of cardiac resynchronization therapy. Cardiovasc Res 2011;89:336-43.

35 Chan BT, Lim E, Chee KH, et al. Review on CFD simulation in heart with dilated cardiomyopathy and myocardial infarction. Comput Biol Med 2013;43:377-85.

36 Aguado-Sierra J, Krishnamurthy A, Villongco C, et al. Patient-specific modeling of dyssynchronous heart failure: a case study. Prog Biophys Mol Biol 2011;107:147-55.

37 Sermesant M, Chabiniok R, Chinchapatnam P, et al. Patient-specific electromechanical models of the heart for the prediction of pacing acute effects in CRT: a preliminary clinical validation. Med Image Anal 2012;16:201-15.

38 Brown AG. Patient-specific local and systemic haemodynamics in the presence of a left ventricular assist device. Department of cardiovascular science. Sheffield: University of Sheffield, 2012.

39 Brown AG, Shi Y, Arndt A, et al. Importance of realistic LVAD profiles for assisted aortic simulations: evaluation of optimal outflow anastomosis locations. Comput Methods Biomech Biomed Engin 2012;15:669-80.

40 Chiu WC, Girdhar G, Xenos M, et al. Thromboresistance comparison of the HeartMate II ventricular assist device with the device thrombogenicity emulationoptimized HeartAssist 5 VAD. J Biomech Eng 2014;136:021014.

41 Farag MB, Karmonik C, Rengier $F$, et al. Review of recent results using computational fluid dynamics simulations in patients receiving mechanical assist devices for end-stage heart failure. Methodist Debakey Cardiovasc J 2014;10:185-9.

42 Ladisa JF Jr, Taylor CA, Feinstein JA. Aortic coarctation: recent developments in experimental and computational methods to assess treatments for this simple condition. Prog Pediatr Cardiol 2010;30:45-9.

43 Pennati G, Corsini C, Hsia TY, et al. Computational fluid dynamics models and congenital heart diseases. Front Pediatr 2013;1:4.

44 Pittaccio S, Migliavacca F, Dubini G, et al. On the use of computational models for the quantitative assessment of surgery in congenital heart disease. Anadolu Kardiyol Derg 2005;5:202-9.

45 van de Vosse FN, Stergiopulos N. Pulse wave propagation in the arterial tree. Annu Rev Fluid Mech 2011;43:467-99.

46 Shi Y, Lawford P, Hose R. Review of zero-D and 1-D models of blood flow in the cardiovascular system. Biomed Eng Online 2011;10:33.

47 Kim HJ, Vignon-Clementel IE, Figueroa CA, et al. On coupling a lumped parameter heart model and a three-dimensional finite element aorta model. Ann Biomed Eng 2009;37:2153-69.

48 Rodriguez L, Thomas JD, Monterroso V, et al. Validation of the proximal flow convergence method. Calculation of orifice area in patients with mitral stenosis. Circulation 1993:88:1157-65.

49 Weese J, Groth A, Nickisch H, et al. Generating anatomical models of the heart and the aorta from medical images for personalized physiological simulations. Med Biol Eng Comput 2013;51:1209-19.

50 Barber DC, Hose DR. Automatic segmentation of medical images using image registration: diagnostic and simulation applications. J Med Eng Technol 2005;29:53-63.

51 Zhao $F$, Xie $X$. An overview of interactive medical image segmentation. Ann BMVA 2013;7:1-22.

52 Kung $E$, Pennati $G$, Migliavacca $F$, et al. A simulation protocol for exercise physiology in Fontan patients using a closed loop lumped-parameter model. J Biomech Eng 2014;136:107001.
53 Zeng $\mathrm{D}$, Boutsianis $\mathrm{E}$, Ammann $\mathrm{M}$, et al. A study on the compliance of a right coronary artery and its impact on wall shear stress. J Biomech Eng 2008; 130:041014.

54 Brown AG, Shi Y, Marzo A, et al. Accuracy vs. computational time: translating aortic simulations to the clinic. J Biomech 2012;45:516-23.

55 Bertoglio C, Barber D, Gaddum N, et al. Identification of artery wall stiffness: in vitro validation and in vivo results of a data assimilation procedure applied to a $3 \mathrm{D}$ fluid-structure interaction model. J Biomech 2014;47:1027-34.

56 Reporting of Computational Modeling Studies in Medical Device Submissions. Rockeville, MD: Draft Guidance for Industry and Food and Drug Administration Staff, 2014

57 Bluestein D, Girdhar G, Einav $S$, et al. Device thrombogenicity emulation: a novel methodology for optimizing the thromboresistance of cardiovascular devices. J Biomech 2013;46:338-44.

58 Pijls NH, Fearon WF, Tonino PA, et al. Fractional flow reserve versus angiography for guiding percutaneous coronary intervention in patients with multivessel coronary artery disease: 2-year follow-up of the FAME (Fractional Flow Reserve Versus Angiography for Multivessel Evaluation) study. J Am Coll Cardiol 2010;56:177-84.

59 Papafaklis Ml, Muramatsu T, Ishibashi Y, et al. Fast virtual functional assessment of intermediate coronary lesions using routine angiographic data and blood flow simulation in humans: comparison with pressure wire-fractional flow reserve. Eurolntervention 2014;10:574-83.

60 U.S. Food and Drug Administration. De novo classification request for FFRCT V. 1.4 (De Novo Summary (DEN130045)). 2014.

61 Sonntag SJ, Li W, Becker M, et al. Combined computational and experimental approach to improve the assessment of mitral regurgitation by echocardiography. Ann Biomed Eng 2014;42:971-85.

62 Swift AJ, Wild JM, Nagle SK, et al. Quantitative magnetic resonance imaging of pulmonary hypertension: a practical approach to the current state of the art. J Thorac Imaging 2014;29:68-79.

63 Morlacchi S, Colleoni SG, Cárdenes R, et al. Patient-specific simulations of stenting procedures in coronary bifurcations: two clinical cases. Med Eng Phys 2013;35:1272-81.

64 Villa-Uriol MC, Berti G, Hose DR, et al. @neurlST complex information processing toolchain for the integrated management of cerebral aneurysms. Interface Focus 2011;1:308-19.

65 Chen D, Müller-Eschner M, Kotelis D, et al. A longitudinal study of type-B aortic dissection and endovascular repair scenarios: computational analyses. Med Eng Phys 2013;35:1321-30.

66 Venkatasubramaniam AK, Fagan MJ, Mehta T, et al. A comparative study of aortic wall stress using finite element analysis for ruptured and non-ruptured abdominal aortic aneurysms. Eur J Vasc Endovasc Surg 2004;28:168-76.

67 Martufi G, Christian Gasser T. Review: the role of biomechanical modeling in the rupture risk assessment for abdominal aortic aneurysms. J Biomech Eng 2013;135:021010.

68 Hunter P, Chapman T, Coveney PV, et al. A vision and strategy for the virtual physiological human: 2012 update. Interface Focus 2013;3:20130004.

69 http://www.avicenna-isct.org (accessed Jul 2015).

70 Donders WP, Huberts W, van de Vosse FN, et al. Personalization of models with many model parameters: an efficient sensitivity analysis approach. Int I Numer Method Biomed Eng 2015;31. Published Online First: 27th May 2015. doi:10.1002/cnm.2727. Epub 2015 Jun 15

71 Stewart S, Hariharan P, Paterson E, et al. Results of FDA's first interlaboratory computational study of a nozzle with a sudden contraction and conical diffuser. Cardiovasc Eng Technol 2013;4:374-91.

72 vph-share.eu. http://vph-share.eu (accessed Jul 2015).

73 Cates CU, Gallagher AG. The future of simulation technologies for complex cardiovascular procedures. Eur Heart J 2012;33:2127-34.

74 http://vph-portal.eu (accessed Jul 2015). 